\title{
Fatigue-crack growth in fresh-water ice: preliminary results
}

\author{
Wilfrid A. Nixon AND LARRy J. Weber \\ Iowa Institute of Hydraulic Research and Department of Civil and Environmental Engineering, \\ University of Iowa, Iowa City, IO 52242-1585, U.S.A.
}

\begin{abstract}
Very little data exist on the fatigue behavior of ice, yet fatigue may have an important role to play in a number of ice failure situations. Whilst reversed-bending tests and cyclic-compression tests have been performed on ice, no attempts have been made previously to measure fatigue-crack growth rates in ice. This paper presents the results of fatigue-crack growth experiments on S2 (i.e. columnar grained with the $c$ axes randomly aligned within the horizontal plane) fresh-water ice. There is clear evidence that crack growth has occurred under cyclic loading but, as yet, the data are insufficient to determine the validity of $\mathrm{d} a / \mathrm{d} N$ versus $\delta K$ type behavior. Preliminary results are presented and the implications of the results are discussed.
\end{abstract}

\section{INTRODUCTION}

\section{The fatigue process}

When a component, of whatever material, is subjected to a time-varying load, cracks may form and grow within the component until failure occur. The first observers of this mode of failure named it, as a result of inaccurate speculation about the micro-mechanical processes involved in the failure, fatigue. Fatigue in metals was first recognized as a mode of component failure in the 1820 s to the 1840 s, primarily in the railroad industry. The phenomenon resulted in the sudden failure of loadbearing parts, such as railway carriage axles, at loads far below the yield strength of the material and under conditions which the components had survived for considerable time prior to failure. There was heated debate on the nature of this phenomenon (see, for example, McConnell, 1850), but the only useful result of this debate was that sudden changes of section (i.e. stressconcentrating features) were to be avoided.

The most important early testing undertaken in an attempt to understand the fatigue process was performed by Wohler (1860). Over many years he tested railway axles by supporting the axles at one end, loading the other end through a bearing, and rotating the supported end. Thus, any point in the axle, except along the neutral axis, experienced a sinusoidally-varying stress cycle with zero mean stress. Wohler presented his data as a plot of applied stress against life-time to failure (often termed $\mathrm{S} / \mathrm{N}$ data) and showed that the number of cycles to failure increased as the amplitude of the applied stress decreased. This can be summarized in an equation of the form

$$
N_{\mathrm{f}}=A(\sigma)^{m},
$$

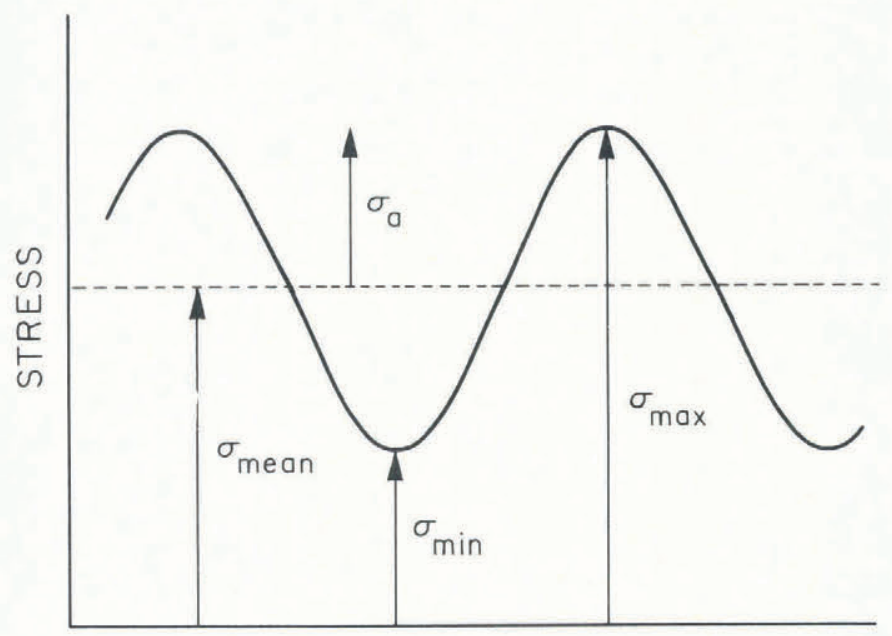

TIME

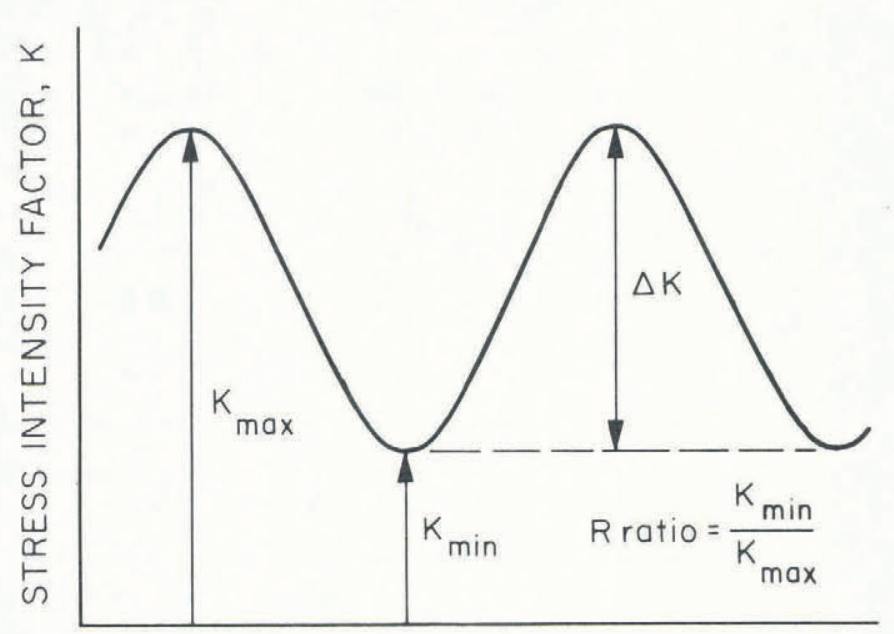

TIME

Fig. 1. Fatigue terminology. 
where $N_{\mathrm{f}}$ is the number of cycles to failure, $A$ and $m$ are empirically derived constants and $\sigma_{\mathrm{a}}$ is the stress amplitude (Fig. 1).

Wohler had shown that fatigue occurred predictably. Ewing and Humphries (1903) demonstrated that persistent slip bands formed on the surface of a polished steel plate under cyclic loading, thus indicating how fatigue loading led to failure. Later (e.g. Forsyth and Stubbington, 1954) it was shown that these slip bands could be extruded from the specimen surface, thus forming surface cracks, generally inclined at $45^{\circ}$ to the loading direction. One such crack would then rotate at the tip to grow at $90^{\circ}$ to the loading direction. This single dominant crack then extended cycle by cycle until failure occurred.

Further understanding of the fatigue-crack growth process required a method of handling near crack-tip stress fields, which are singular at the crack tip. Irwin (1957) developed the stress intensity factor, $K$, which expresses the near-tip stress field in terms of the specimen geometry (including the crack length) and the far-field stress rate. Paris and others (1961) showed that the crack-growth rate per cycle $(\mathrm{d} a / \mathrm{d} N)$ was a function of $\Delta K$, the applied stress intensity factor range. This can be summarized by an equation of the form

$$
\frac{\mathrm{d} a}{\mathrm{~d} N}=c(\Delta K)^{p},
$$

where again $C$ and $p$ are empirically-derived constants. The fatigue process, then, consists of three phases. First, a crack is initiated, unless some flaws already exist within the component. Next, a single dominant crack grows at a rate governed by crack-tip behavior. Finally, failure may occur either when the maximum value of the applied stress intensity factor, $K_{\max }$ (Fig. 1), exceeds $K_{\text {Ic }}$ (the fracture toughness of the material) for the specimen material, or when the uncracked ligament yields. A more complete discussion of fatigue can be found in the review by Schijve (1979) and the text by Broek (1982).

\section{The fatigue of ceramics}

Whilst most metals can be damaged by fatigue loading, ceramics are not, in general, susceptible to this form of failure. This is because most ceramics exhibit insufficient crack-tip plasticity for cycle-by-cycle crack growth (Wiederhorn and others, 1973). Rather, cracks will grow in ceramics under load in a corrosive environment. This phenomenon is termed static fatigue, although a more accurate description would be stress-corrosion cracking. Cyclic loading does not enhance stress-corrosion cracking in ceramics at ambient temperatures. However, at absolute temperatures greater than $50 \%$ of a ceramic's melting point, there is some evidence that the more usual form of fatigue observed in metals may also be occurring in ceramics. Kossowsky (1973) found higher growth rates than expected from static fatigue considerations when loading $S i_{3} N_{4}$ at $1300^{\circ} \mathrm{C}$. He also found micrographic evidence of increased crack-tip plasticity, suggesting that the higher temperatures may have allowed sufficient crack-tip plasticity (through creep processes) to develop for "classical" fatigue to occur.

\section{The fatigue of ice}

Fatigue behavior in ice is of interest for three reasons.
First, ice may be considered a ceramic, which can be tested at very high ( $95 \%$ of the melting point) temperatures with relative ease. By studying ice, significant information which is relevant to ceramic behavior under high temperature conditions may thus be gained. The transparency of ice adds an extra benefit in this regard since it allows the development of damage to be monitored. Second, much of the ice found in nature suffers fatigue loading through wave and tidal action. An iceberg at sea, for example, suffers fully reversed bending as waves pass it by. Third, when ice is used as part of a structure, such as a runway or a bridge, the loading is frequently repetitive and may lead, through fatigue, to the degradation of the structure.

That ice in nature does experience cyclic loading is evident from field measurements. Kristensen and others (1982) measured the alternating strain amplitude on an Antarctic iceberg in $2 \mathrm{~m}$ seas, and found values between 2 and 5 microstrain $\left(\right.$ strain $\left.\times 10^{-6}\right)$. Similar strain-gauging experiments by Goodman (unpublished) on landfast ice in Bylot Sound and Forteau Bay gave strain amplitudes on the ice surface of 5 microstrain.

Relatively little work on fatigue behavior in ice has been performed. Kartashkin (1947) performed compressive fatigue tests (i.e. the load throughout the cycle was compressive) on large blocks of fresh-water ice, and found a decrease in strength (from static loading) of up to $25 \%$ as a result of the fatigue loading, although his definition of strength in this regard is not clear. Similar tests were performed by Tabata and Nohguchi (1980), who worked with small saline-ice samples, and by Mellor and Cole (1981), who worked with fresh-water, polycrystalline ice samples. Both found that the ice exhibited a modified creep response, rather than typical fatigue behavior. More recently, Cole (1990) has performed fully reversed uniaxial compression-tension tests using a newly developed testing apparatus (Cole and Gould, 1989). The purpose of these tests, however, has been to gain insight into micro-mechanical behavior of ice, rather than to observe fatigue-crack growth. Goodman (unpublished) reported unsuccessful fatigue-crack growth tests on fresh-water ice. Nixon and Smith $(1984,1987)$ performed cyclic bending tests using a Wohler-type rig, and found clear evidence of typical S/N type behavior. This was the first clear indication that fatigue-crack growth might occur in ice, but the nature of the tests made it impossible to determine crack-growth rates within the ice.

The purpose of this paper is to report preliminary experiments to determine the fatigue-crack growth rate in ice. The ice tested was fresh-water S2 columnar ice, in two orientations. One orientation had the axes of the crystal columns parallel to the crack front (termed "horizontal"), whilst, for the other orientation, the columns were perpendicular to the crack front (termed "vertical"). These orientations are shown in Figure 2. Testing was performed at a temperature of $-5.0 \pm 0.3^{\circ} \mathrm{C}$ (with the variation occurring over a long time period, corresponding to defrost cycles in the cold room), and at a frequency of $5 \mathrm{~Hz}$. Applied-stress intensity factors ranged up to $80 \mathrm{kPa} \sqrt{m}$. The results give clear indications of measurable crack growth bıt, as yet, data are too sparse to provide meaningful $\mathrm{d} a / \mathrm{d} N$ versus $\Delta K$ curves. 

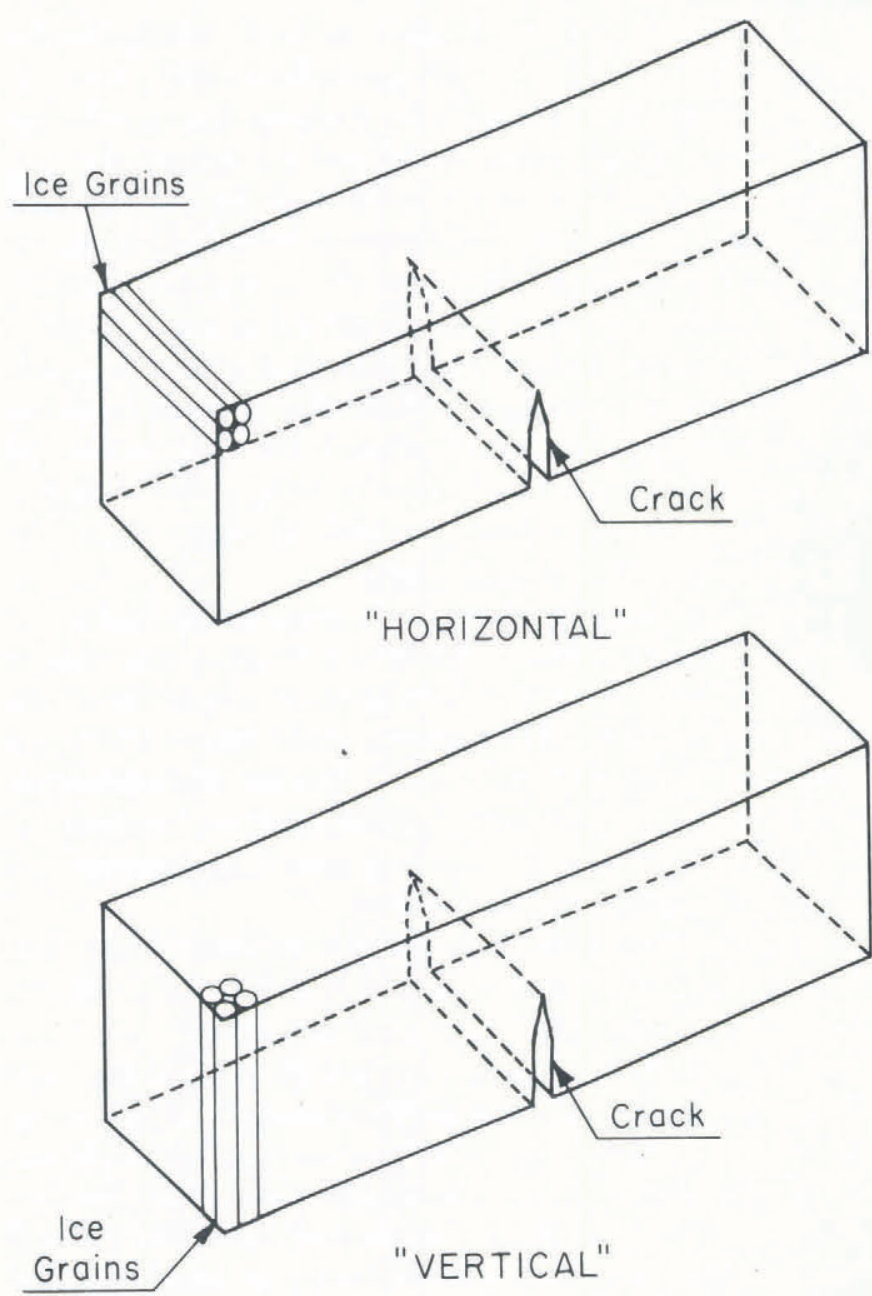

Fig. 2. Grain orientation in test samples.

\section{EXPERIMENTAL TECHNIQUE}

Ice samples were made in the Iowa Institute of Hydraulic Research (IIHR) cold room towing tank, by the wet-seed process. The water in the tank is supercooled and, in still air, a fine mist of water particles is created. These water droplets freeze while in the air and form nuclei from which the ice sheet grows when they touch the water. The ice formed in this process is fine-grained columnar S2 ice with $c$ axes randomly oriented in the horizontal plane (as determined by measurements made on a universal stage). Figure 3 shows thin sections of a typical beam, taken both vertically (so as to show the columns) and horizontally (to show column diameters, which are $2.4 \pm 0.8 \mathrm{~mm}$, as measured by the linear intercept method). Samples were cut considerably over-size from the ice sheet with a chain saw. After further trimming on a band saw, the specimens were milled to the test dimensions of $50 \times 100 \times 400 \mathrm{~mm}^{3}$. The dimensions of the milled specimens were accurate to $\pm 0.25 \mathrm{~mm}$. Samples were milled at the test temperature $\left(-5^{\circ}\right) \mathrm{C}$ ) one day prior to testing. Immediately prior to testing, a slot was cut into the specimen on a band saw to a depth of $40 \mathrm{~m}$. The sample was then placed in the four-point bend rig (as shown in Fig. 4) for pre-loading and crack initiation (described below). Figure 5 shows the geometry of the sample schematically.

For the four-point bend-loading geometry used herein,

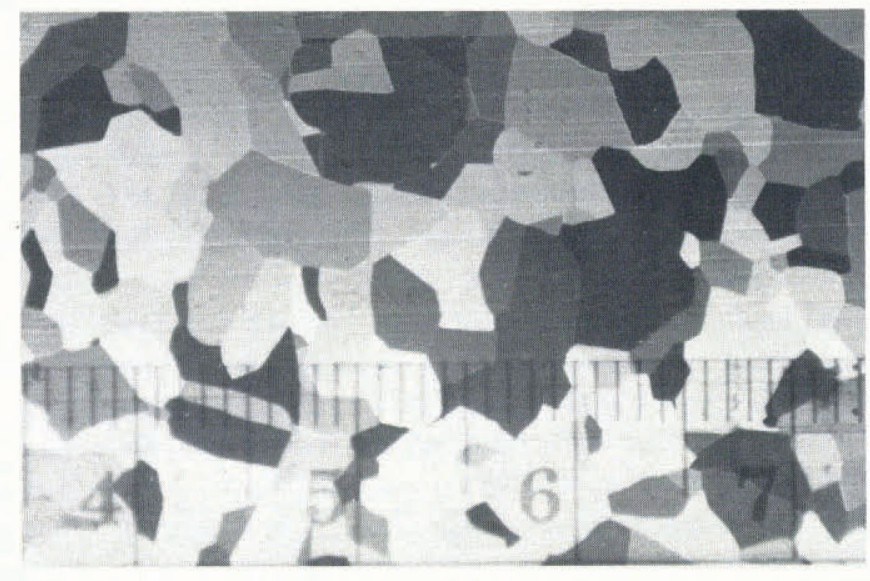

a
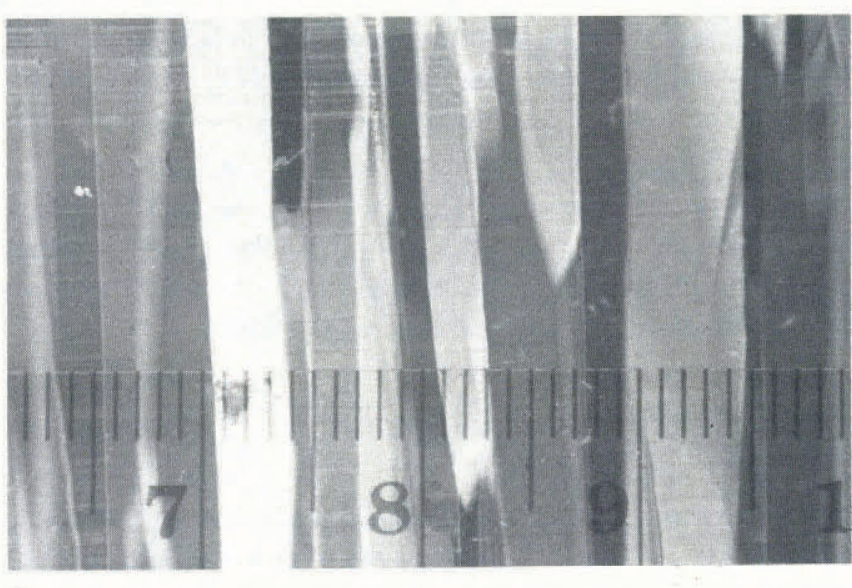

b

Fig. 3. (a) Longitudinal thin section of beam.

(b) Transverse thin section of beam.

the value of $K_{1}$ is given by (Clausing, 1969)

$$
K_{1}=\frac{3 P L \sqrt{a}}{t W^{2}} Y,
$$

where $P$ is the applied load, $L$ is the distance between outer and inner load-application points $(=75 \mathrm{~mm}$ in this case), $t$ is the specimen thickness $(=50 \mathrm{~mm}), W$ is the specimen depth $(=100 \mathrm{~mm})$ and $a$ is the crack length. $Y$ is given by

$$
Y=1.992-2.468 \eta+12.97 \eta^{2}-23.17 \eta^{3}+24.80 \eta^{4},
$$
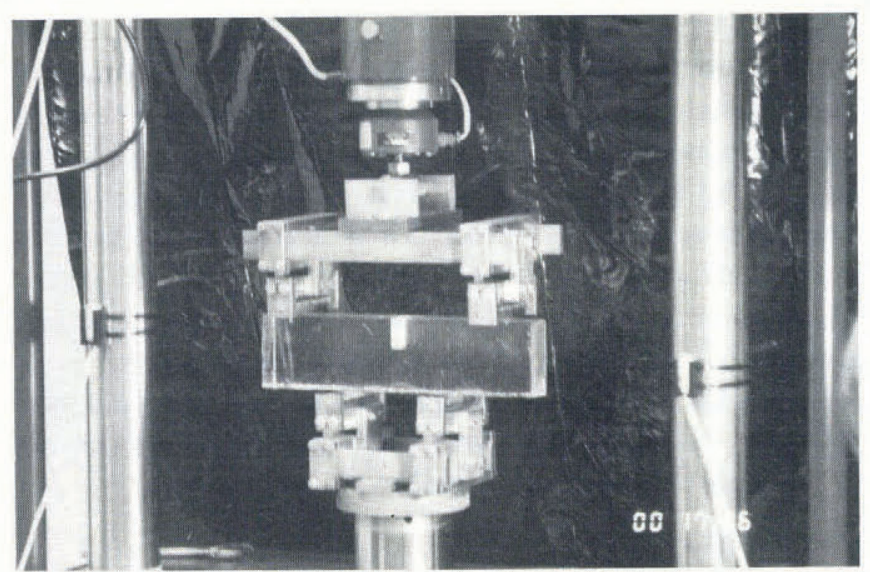

Fig. 4. Sample placed in test machine. 


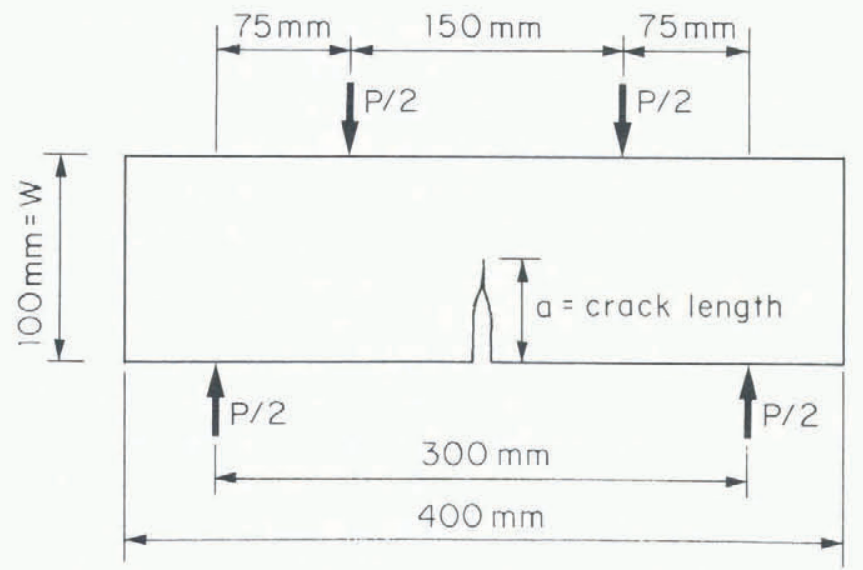

Fig. 5. Sample-loading geometry.

where $\eta=a / W$. This specimen geometry has been used before in ice, by Dempsey and co-workers (see, for example, Wei and others, 1990) to measure the fracture toughness of ice. Recent work by Dempsey (personal communication, 1990) suggests that a good method of producing a sharp crack at the tip of a band-saw slot for this geometry is to load the beam to $180 \mathrm{~N}$ and scribe a crack across the tip of the band-saw slot with a razor blade, while the beam is under load. This causes a crack to pop in a distance of approximately $6-8 \mathrm{~mm}$. Although this does not allow close control of the starting-crack length, the evidence of Wei and others (1990) suggests quite clearly that this provides the best possible crack within the ice. This method was used in the testing described herein to obtain a starter crack for the fatigue samples.

As soon as the slot had been sharpened into a crack by the above method, testing was started. An MTS servo-hydraulic testing machine was used, under load control. The machine provided a load which varied sinusoidally at $5 \mathrm{~Hz}$, with mean and amplitude at set levels. Careful monitoring of the output of the load cell (using a PC based data-acquisition system) showed that the measured load did not deviate from the specified true sine wave by more than $4 \%$ at any point in any of the tests. The testing described herein was performed with $R$-ratios (defined in Fig. 1) in the range of 0.07 to 0.23 . Future testing will examine the effect of $R$-ratio on fatigue-crack growth. Table 1 shows the values of $\Delta K$ used in this series of tests.

Table 1. Test parameters

\begin{tabular}{cccc}
\hline Test no. & Type & $\Delta K\left(\mathrm{kPa} \mathrm{m}^{1 / 2}\right)$ & $R$-ratio \\
\hline 4H & Horizontal & 123 & 0.07 \\
$5 \mathrm{H}$ & Horizontal & 109 & 0.16 \\
$6 \mathrm{H}$ & Horizontal & 108 & 0.17 \\
$7 \mathrm{H}$ & Horizontal & 80 & 0.20 \\
$7 \mathrm{~V}$ & Vertical & 107 & 0.07 \\
$8 \mathrm{~V}$ & Vertical & 86 & 0.23 \\
$9 \mathrm{~V}$ & Vertical & 85 & 0.22 \\
$10 \mathrm{~V}$ & Vertical & 80 & 0.18 \\
\hline
\end{tabular}

Crack length was measured using a travelling microscope mounted on a vernier-positioning gauge. This microscope can measure distances to an accuracy of $\pm 2.5 \times 10^{-3} \mathrm{~mm}$. However, the crack length in the ice was measurable to an accuracy of $\pm 0.05 \mathrm{~mm}$. This discrepancy arises, at least in part, because of the transparency of the ice. It is possible to focus the microscope at any point of the crack front through the ice. Thus, the observer can view, first, the crack tip on the side of the ice closest to the microscope, then, by adjusting the focus, the whole crack front. At all times, every attempt was made to measure the crack length at the ice surface. However, sometimes there were difficulties associated with this approach because of surface sublimation. The surfaces of the samples were protected by a thin plastic coating but, even so, sublimation occurred, as indicated by slight rounding of the previously sharp $\left(90^{\circ}\right)$ sample edges. No attempt was made to measure the extent of sublimation by, for example, weighing samples before and after testing, because the dimensional reduction caused by sublimation was not measurable with vernier calipers.

By observing the length of a crack that was not growing over a long period of time, an estimate of the accuracy of the measurements was obtained. All crack-length measurements were taken with the sinusoidal loading stopped, and with the sample under the minimum load in the cycle. Typically, a crack-length reading took about 5 min.

\section{RESULTS AND DISCUSSION}

Eight tests have been successfully performed at relatively high values of $K_{\max }$ (typically, $K_{\max } \approx 0.95 K_{\mathrm{Ic}}$ ), with four tests being on "horizontal" ice and four on "vertical" ice. The results indicate three periods of behavior. First, as soon as loading begins, there is a period of crack growth. This lasts typically 20000 cycles, and produces

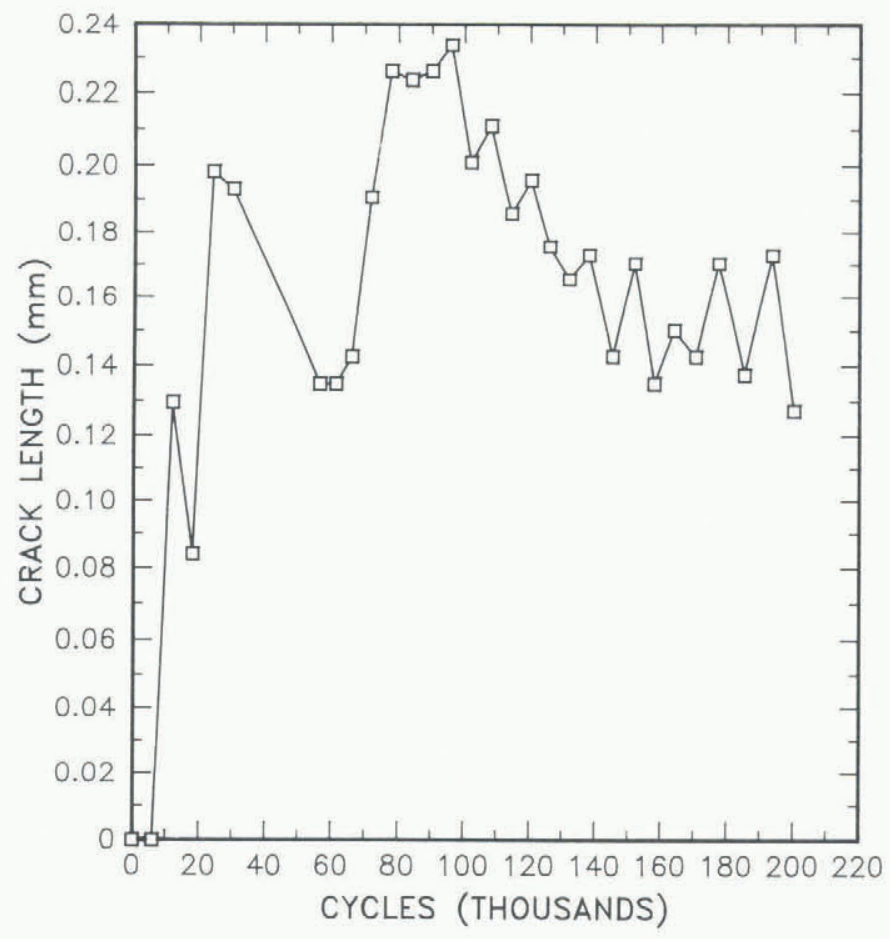

Fig. 6. Crack growth data showing measurement accuracy. 


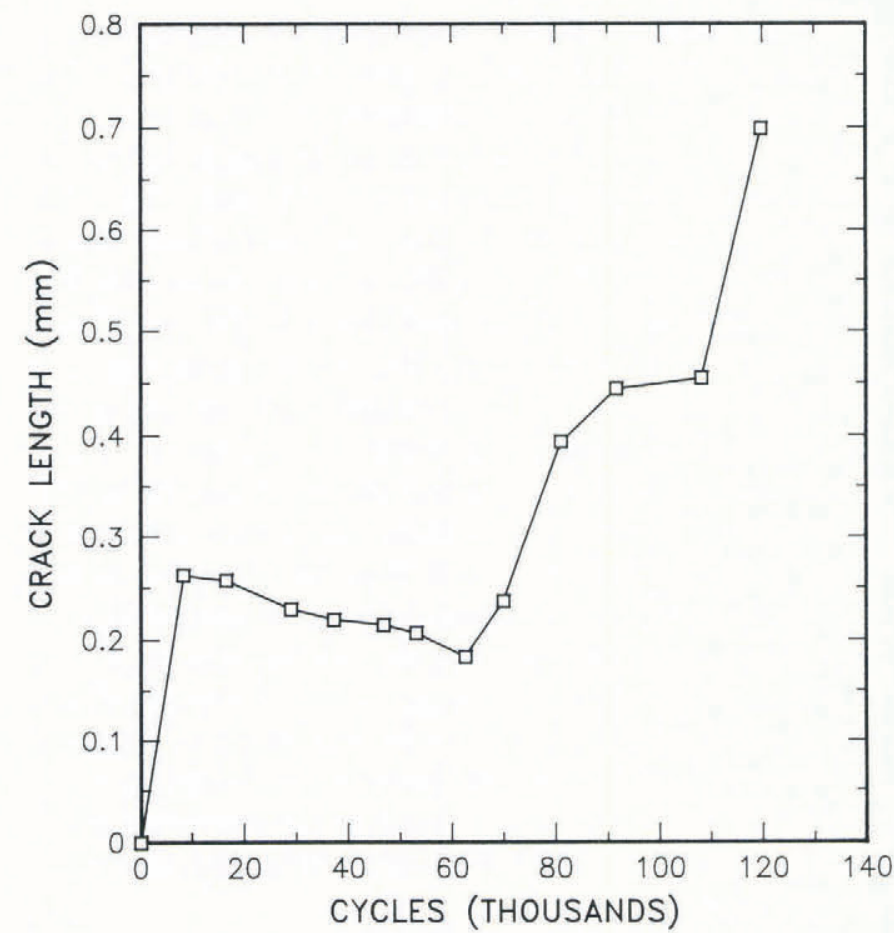

Fig. 7. Crack growth data showing initial growth, no-growth period and growth to failure.

crack growth of up to $0.50 \mathrm{~mm}$. There is then a period of no growth (i.e. when any growth that might be occurring is obscured by the scatter in the crack-growth measurements). This period is clearly indicated in Figure 6, for a horizontal sample. Initial growth, in this case, was of $0.175 \mathrm{~mm}$ and took 20000 cycles. There then followed a period of no growth lasting for 180000 cycles. The sample then failed before any further measurable growth was observed after a total life of 217618 cycles. Note that this no-growth period indicates clearly the level of accuracy obtainable on the crack-length measurements. The final period occurs after the no-growth period and can be termed growth to failure. In tests to date, this third period of behavior has lasted up to 60000 cycles and has produced crack growth of up to $0.50 \mathrm{~mm}$. Figure 7 shows such behavior in a "vertical" specimen. Table 2 summarizes these results.
The three different stages are relatively simply explained in a qualitative manner. The first stage of relatively easy crack growth occurs as the sharp crack grows through the immediate damage zone associated with its formation. Beyond the damage zone, there may be a region of residual compressive stress which has formed as a result of the damage associated with the crack-formation process. Growth through this zone is slow and, because of the limitations of crack-length measurement, cannot be discerned. This constitutes the no-growth region. Finally, once the crack emerges from the slow-growth zone, crack growth can begin in earnest. Because of the high values of $\Delta K$ and $K_{\max }$ used in this study, the amount of growth and number of cycles in this final stage of the process have been small. Nonetheless, they are present and measurable, giving clear evidence of fatigue-crack growth within ice. Given the small amount of data, it would not be meaningful to attempt to develop $\mathrm{d} a / \mathrm{d} N$ versus $\Delta K$ curves at this time. Thus, it cannot yet be determined whether ice follows the Paris law of fatigue-crack growth (Equation (2)) or whether some other functionality is a better description of the process. Further work should provide more data in this regard.

Table 2 shows the growth data for both vertically and horizontally oriented specimens. No clear trend can be determined from the data regarding which orientation provides faster growth, though three of the four horizontal samples showed no final growth, whereas three of the four vertical samples did show final growth. This may reflect the fact that, in the horizontal samples, only one grain lies along the crack front. If this is favourably oriented for growth then growth should be reasonably rapid and easily observed. Conversely, if this crack-front grain is not favourably oriented, then little or no growth will be observed. The vertical samples, having more grains along the crack front, provide a crystallographically "averaged" crack-growth rate. Crystallographic studies are planned to explore this issue more completely.

\section{CONCLUSIONS}

Although the work described in this paper is preliminary, the following conclusions can be drawn.

- Measurable crack growth under fatigue loading does occur in S2 columnar fresh-water ice, at temperatures

Table 2. Crack growth data

\begin{tabular}{rrrccrr}
\hline Test no. & $\begin{array}{c}\text { Initial } \\
\text { growth } \\
(\mathrm{mm})\end{array}$ & $\begin{array}{c}\text { Cycles } \\
\text { in phase } \\
1\end{array}$ & $\begin{array}{c}\text { No-growth } \\
\text { cycles } \\
\text { (Phase 2) }\end{array}$ & $\begin{array}{c}\text { Final } \\
\text { growth } \\
(\mathrm{mm})\end{array}$ & $\begin{array}{c}\text { Cycles } \\
\text { in phase } \\
3\end{array}$ & $\begin{array}{r}\text { Total } \\
\text { time } \\
(\mathrm{s})\end{array}$ \\
\hline $4 \mathrm{H}$ & 0.10 & 10000 & - & - & 4758 & 2950 \\
$5 \mathrm{H}$ & 0.03 & 10000 & - & - & 11016 & 4200 \\
$6 \mathrm{H}$ & 0.64 & 10000 & 56415 & 0.49 & 65885 & 26460 \\
$7 \mathrm{H}$ & 0.20 & 24004 & 185422 & - & 8192 & 43520 \\
$7 \mathrm{~V}$ & 0.23 & 10800 & 7600 & - & 2054 & 4090 \\
$8 \mathrm{~V}$ & 0.26 & 8296 & 61704 & 0.46 & 95646 & 33130 \\
$9 \mathrm{~V}$ & 0.41 & 20364 & - & 0.17 & 21043 & 8280 \\
$10 \mathrm{~V}$ & 0.23 & 37571 & 21936 & 0.13 & 4384 & 12780 \\
\hline
\end{tabular}


of $-5^{\circ} \mathrm{C}$ and frequencies of loading of $5 \mathrm{~Hz}$.

- The crack-growth behavior breaks into three zones. First, there is rapid growth through what may be a damage zone associated with the crack-formation method. Second, there is a period of very slow (essentially, using current techniques, unmeasurable) crack growth, through what might be a region of residual compressive stress associated with the crackformation process. Finally, there is a second period of measurable crack-growth which leads to failure.

- Further data are needed to determine the validity or otherwise of a Paris type law relating crack-growth rate $(\mathrm{d} a / \mathrm{d} N)$ and the applied stress intensity factor range $(\Delta K)$.

\section{ACKNOWLEDGEMENTS}

The authors are grateful to Prof. John Dempsey of Clarkson University and Mr David Cole of the U.S. Army Cold Regions Research and Engineering Laboratory for helpful discussions on the topic of fatigue-crack growth in ice. The project is funded by grant number DAAL0389-K-0069 from the Army Research Office. This support is gratefully acknowledged.

\section{REFERENCES}

Broek, D. 1982. Elementary engineering fracture mechanics. The Hague, Martinus Nijhoff Publishers.

Clausing, D.P. 1969. Crack stability in linear elastic fracture mechanics. Int. J. Fract. Mech., 5(3), 211-227.

Cole, D.M. 1990. Cyclic loading of saline ice: initial experimental results. Proceedings of the Ninth International Conference on Offshore Mechanics and Arctic Engineering ... Houston, Texas, February 18-23, 1990. Vol. IV. New York, American Society of Mechanical Engineers, 265-271.

Cole, D.M. and L.D. Gould. 1989. Uniaxial tension/compression tests on ice - preliminary results. Proceedings of the Eighth International Conference on Offshore Mechanics and Arctic Engineering ... The Hague, The Netherlands, March 1923, 1989. Vol. IV. Arctic and polar technology. New York, American Society of Mechanical Engineers, 37-41.

Ewing, J.A. and J.C.W. Humphries. 1903. The fracture of metals under repeated alternations of stress. Philos. Trans. R. Soc. London, Ser. A, 200, 241-249.

Forsyth, P.J.E. and C.A. Stubbington. 1954. The slip band extrusion effect observed in some aluminium alloys subjected to cyclic stresses. J. Inst. Met., 83, 395-399.

Goodman, D.J. Unpublished. Creep and fracture of ice and surface strain measurements on glaciers and sea
Nixon and Weber: Fatigue-crack growth in fresh-water ice ice. (Ph.D. thesis, University of Cambridge, 1977.)

Irwin, G.R. 1957. Analysis of stresses and strains near the end of a crack traversing a plate. Trans. Am. Soc. Mech. Eng. E, J. Appl. Mech., 24, 361-364.

Kartashkin, B.D. 1947. Experimental'nyye issledovaniya fiziko-mekhanic heskikh svoystv l'da [Experimental studies of the physico-mechanical properties of ice]. Tsentral'nyy Aerogidrodinamicheskiy Institut. Trudy 607.

Kossowsky, R. 1973. Cyclic fatigue of hot pressed $\mathrm{Si}_{3} \mathrm{~N}_{4}$. J. Am. Ceram. Soc., 56, 531-535.

Kristensen, M., V.A. Squire, and S.C. Moore. 1982. Tabular icebergs in ocean waves. Nature, 297(5868), 669671.

McConnell, J.E. 1850. On the deterioration of railway axles \& co. Proc. Inst. Mech. Eng., 2, 5-19.

Mellor, M. and D. Cole. 1981. Cyclic loading and fatigue in ice. Cold Reg. Sci. Technol., 4(1), 41-53.

Nixon, W.A. and R.A. Smith. 1984. Preliminary results on the fatigue behaviour of polycrystalline freshwater ice. Cold Reg. Sci. Technol., 9(3), 267-269.

Nixon, W.A. and R.A. Smith. 1987. The fatigue behaviour of freshwater ice. J. Phys. (Paris), 48, Colloq. C1, 329-334. (Supplément au 3.)

Paris, P.C., M. Gomez, and W.E. Anderson. 1961. A rational analytic theory of fatigue. Trends Eng., 13(1).

Schijve, J, 1979. Four lectures on fatigue crack growth. Eng. Fract. Mech., 11, 167-221.

Tabata, T. and Y. Nohguchi. 1980. Failure of sea ice by repeated compression. it In Tryde, P., ed. International Union of Theoretical and Applied Mechanics. Physics and mechanics of ice. Symposium Copenhagen, ... 1979. ... Berlin, Springer-Verlag, 351-362.

Wei, Y., S.J. DeFranco, and J.P. Dempsey. 1990. Notch acuity effects on the fracture toughness of freshwater ice. Proceedings of the Ninth International Conference on Offshore Mechanics and Arctic Engineering ... Houston, Texas, February 18-23, 1990. Vol. IV. New York, American Society of Mechanical Engineers, 253-257.

Wiederhorn, S.M., B.K. Hockey, and D.E. Roberts. 1973. The effect of temperature on the fracture of sapphire. Philos. Mag., 28, 783-796.

Wohler, A. 1860. Versuche über die Festigkeit der Eisenbahn Wagenachsen. Zeitschrift für Bauwesen, summarized in English in Engineering, 4, August 23rd, 1867, 160-161.

The accuracy of references in the text and in this list is the responsibility of the authors, to whom queries should be addressed. 